\title{
VÍDEOS E MÚSICAS UTILIZADOS COMO INSTRUMENTOS MOTIVADORES NO PROCESSO ENSINO-APRENDIZAGEM
}

\author{
S. R. MORAES, A. HAIDUK, F. CHARAVARA, L. G. S. BAZIUK, J. SLOBODA, P. MAIA e J. R. C. ROCHA \\ Universidade Estadual do Paraná (UNESPAR) \\ jrcaetanorocha@ig.com.br*
}

Artigo submetido em outubro/2014 e aceito em abril/2015

DOI: $10.15628 /$ holos.2015.2497

\section{RESUMO}

Neste trabalho são apresentados os resultados obtidos durante as atividades realizadas no processo de capacitação de professores de Química e Ciências do ensino básico de União da Vitória - PR. Dentre os objetivos dessas atividades estavam à aplicação, das mesmas, em salas de aulas do ensino fundamental II e médio, onde os professores-alunos eram regentes. Para que esses objetivos fossem efetivados foram utilizadas atividades metodológicas diversificadas para auxiliar na promoção do conhecimento de conceitos das disciplinas de Química no ensino médio e de Ciências no ensino fundamental II, tais como, vídeos, música e atividades lúdicas. Nessas atividades abordou-se os conteúdos de biologia celular para o ensino fundamental II e avaliouse as formas e fontes energéticas em relação a biodiversidade. Durante a aplicação das atividades aos professores e posteriormente aos seus alunos se percebeu o forte interesse pelas atividades e a motivação pelos conteúdos discutidos. Fato que é nítido quando analisados os dados estatísticos extraídos dos questionários respondidos pelos professores e pela leitura dos relatórios produzidos pelos mesmos. Nesses resultados se percebe que mais de $90 \%$ dos professoresalunos consideraram as atividades com pontuação acima de oito, ou seja, consideraram as atividades acima de boas e, portanto quase ótimas.

PALAVRAS-CHAVE: vídeo, música, ensino-aprendizagem, metodologias diversificadas.

\section{VIDEOS AND SONGS USED AS MOTIVATIONAL TOOLS IN THE TEACHING- LEARNING PROCESS}

\begin{abstract}
This paper presents the results obtained during the activities carried out in the training process of Chemistry teachers and Sciences of basic education of União da Vitória - PR. Among the objectives of these activities was the implementation, of the same, in classrooms of elementary school and high school, where teachersstudents were regents. For these objectives were hired diverse methodological activities were used to assist in promoting awareness of concepts of Chemistry disciplines in high school and Science in elementary school II, such as videos, music and fun activities. In these activities addressed to the cell biology of content
\end{abstract}

for elementary school and evaluated the forms and sources of energy in relation to biodiversity. During the implementation of activities to teachers and then the students if realized strong interest in activities and motivation for the contents discussed. This fact is clear when analyzing the statistical data taken from questionnaires answered by teachers and reading the reports produced by them. These results can be seen that over $90 \%$ of teachers considered the activities with scores above eight, that is, considered the above good activities and therefore almost great.

KEYWORDS: video, song, teaching-learning, diversified methodologies. 


\section{INTRODUÇÃO}

A partir do curso de "Capacitação de Professores de Ciências e Química do Ensino Básico para o Desenvolvimento de Atividades Motivadoras do Aprendizado", do Programa Universidade Sem Fronteiras (Apoio às Licenciaturas), que foi financiado pela Secretaria de Ciência e Tecnologia e Ensino Superior do Estado do Paraná (SETI) foram obtidos relevantes resultados, sendo que parte deles originou este trabalho. Os objetivos neste caso foram o de analisar o nível de aceitação de vídeos educativos e músicas pelos professores do ensino básico que participaram do referido curso de capacitação. Bem como, a aplicação dos mesmos em sala de aula onde os professores-alunos eram regentes. Nestes casos, os principais propósitos de aplicação destes recursos metodológicos foram o de introduzir metodologias diversificadas e aplicáveis no processo ensino-aprendizagem com o intuito de motivar o aluno para a aprendizagem de conteúdos programáticos dessas disciplinas.

Devido à globalização e aos avanços tecnológicos ocorridos nas comunicações e na informática, e ainda aliados à facilidade de comunicação existente hoje entre as pessoas, seja presencial ou virtualmente, os docentes necessitam a cada dia diversificar sua forma de atuação em sala de aula. Esse fato se torna necessário para que sua aula tenha atrativos suficientes para que os seus alunos consigam se motivar para o processo ensino-aprendizagem.

A visão behaviorista focalizada no papel da recompensa e do reforço da motivação é um processo adequado para justificar e entender o processo motivador aqui discutido. Mais precisamente, a motivação intrínseca que ocorre quando não há recompensa aparente pela realização da tarefa, a não ser a tarefa em si. Neste caso, a motivação intrínseca está relacionada principalmente ao envolvimento dos alunos com as tarefas de aprendizagem pela preferência por desafios, por persistência, por esforços, pelo uso de estratégias de aprendizagem, além de outros resultados positivos (GUIMARÃES; BORUCHOVITCH, 2004).

Assim, existe um enorme desafio para os professores, podendo-se falar ainda da necessidade de mudança de paradigmas educacionais, frente a uma educação tecnológica que já se firma como realidade. Conjuntamente, visando o uso de tecnologias na educação, na qualidade de recursos de aprendizagem, nas situações que se criam, nos ambientes que se desenvolvem, visto que, todos esses itens são essenciais para a ampliação do processo de aprendizagem, do envolvimento e da capacidade de interação dos alunos (SANTOS; TAUROCO, 2007). Adicionalmente é necessário que essas novas práticas pedagógicas se relacionem harmonicamente com esses novos recursos e, principalmente, sejam centradas na aprendizagem do aluno (BEHAR; TORREZZAN, 2009).

Novas tecnologias tendem a provocar mudanças significativas na Educação, tanto na instituição escola, quanto na qualificação docente. Assim, sua forma de uso e aplicabilidade tem causado grande preocupação entre os educadores (UGIONI, 2009).

Segundo Moran (2000) existe uma ampla variedade de técnicas metodológicas que o professor pode utilizar para organizar sua comunicação com o educando, tanto para introduzir um tema, como para trabalhar com os mesmos presencialmente ou não, e inclusive para avaliálos sobre temas correlatos. 
Dentre essas técnicas está o uso do vídeo que auxilia o professor, atraindo e motivando o educando em relação ao conteúdo que será abordado, podendo inclusive aproximar o educando do seu cotidiano, das linguagens de aprendizagem e comunicação da sociedade e, ainda, introduz novas questões no processo educacional (MORAN, 1995).

Os Parâmetros Curriculares para o Ensino Médio indicam a necessidade de se aplicar as tecnologias de comunicação e informação na escola, no trabalho e em outros contextos relevantes para a vida do aluno (BRASIL, 2000).

Neste sentido, outra forma para motivar os alunos no processo ensino-aprendizagem é a música. Contudo, esta é concebida mais como um recurso para o desenvolvimento de outras atividades e não, propriamente, como campo de conhecimento com valores, conteúdos e objetivos específicos (SOUZA, 2002).

Hummes (2004) relembra as ideias de Merriam, ressaltando a importância da música para a sociedade. Principalmente, quando o mesmo apresenta as concepções e as funções da música, categorizando as concepções em: I) Expressão emocional; II) Prazer estético; III) Divertimento / Entretenimento; IV) Comunicação; V) Representação Simbólica; VI) Reação física; VII) Impor conformidade às normas sociais; VIII) Validação das instituições sociais e dos rituais religiosos; IX) Contribuição para a continuidade e estabilidade da cultura e X) Contribuição para a integração da sociedade. Ainda aponta que a música é indispensável para a promulgação apropriada das atividades que constituem uma sociedade, sendo inclusive um comportamento humano universal.

O papel do professor na utilização dessas novas tecnologias está diretamente relacionado ao processo de selecionar e de planejar o uso dos materiais escolhidos, para que os mesmos cumpram a sua finalidade no processo educacional. Desta forma, neste processo está inclusa a pesquisa e o desenvolvimento de estratégias de utilização desses materiais, para que possam tirar partido da desatualização do conteúdo e do formato educativo, em contextos concretos (FALKEMBACH, 2005).

Em busca desses pressupostos é que esse trabalho foi conduzido e desenvolvido. Porém para Denzin e Lincoln (2000) todas essas técnicas e metodologias de trabalho são consideradas nulas, se às entrevistas não acontecerem durante o processo de pesquisa, ou, mesmo durante a aplicação em sala de aula, visto que a entrevista é uma conversa, na qual impera a arte de fazer questionamentos e ouvir. Além disso, devido à forte crença da sociedade no seu poder de geração de informações úteis, "a entrevista se torna uma parte indubitável da nossa mediada cultura de massa". Assim, apoiar-se nas entrevistas como fonte direta de informação pressupõese que as mesmas resultam em retratos verdadeiros e acurados (FONTANA; FREY, 2000). Portanto todos esses pressupostos - música, vídeo, atividades lúdicas e entrevistas, além de relatórios produzidos pelos professores-alunos - foram utilizados para avaliar o processo motivador que acontece quando atividades diversificadas são utilizadas em sala de aula, visto que diversificar atividades no processo ensino-aprendizado é motivador e faz com que os alunos consigam adquirir o conhecimento por um período de tempo maior (MORAES; WISNIEWSKI; ROCHA, 2014). 


\section{METODOLOGIA E DESENVOLVIMENTO}

Durante o curso de capacitação foram utilizados vídeos e músicas, bem como atividades lúdicas como instrumentos metodológicos para motivação do aprendizado. Isto ocorreu em duas reuniões realizadas, em datas distintas do curso de "Capacitação de Professores de Ciências e Química do Ensino Básico para o Desenvolvimento de Atividades Motivadoras do Aprendizado" realizado na Faculdade Estadual de Filosofia, Ciências e Letras de União da Vitória - PR. Posteriormente os professores capacitados aplicaram as atividades desenvolvidas nas escolas estaduais paranaenses dos municípios de União da Vitória, São Mateus do Sul, Cruz Machado, Porto Vitória, Paulo Frontin, Bituruna, General Carneiro, Paula Freitas e Antonio Olindo.

Na primeira reunião exibiu-se o vídeo denominado "Biologia: Tudo sobre a Célula" (YOUTUBE, 2010a) e, em seguida, distribuiu-se aos professores-alunos um texto com as informações apresentadas no vídeo. Também foram incluídas nesse texto questões sobre o tema, sendo essa parte denominada de "Perguntas e Respostas". No segundo momento do encontro aplicou-se a atividade lúdica, denominada de "Jogo da Memória". Nessa atividade, em metade dos cartões se empregou palavras chaves relacionadas ao conteúdo abordado no vídeo e na outra metade dos cartões se utilizou de imagens representativas daquelas palavras chaves.

Na segunda reunião foi apresentado o vídeo "Paraná Bio: Descobrindo os Corredores da Biodiversidade" - Parte 1 (YOUTUBE, 2010b). Aos professores-alunos foi sugerido que poderia ser preparado outro jogo da memória similar ao que foi apresentado na reunião anterior para discutir e avaliar os conteúdos abordados nesse segundo vídeo.

Em seguida, apresentou-se a problemática da necessidade energética que muitas vezes põe em risco a biodiversidade. Desta maneira, ministrou-se uma aula teórico-expositiva sobre "Formas e Fontes de Energia" e como caracterização de obtenção de fonte energética ouviu-se a música "Sobradinho". Por fim, se discutiu os prós e os contras da escolha dessa fonte energética, avaliando não somente os fatores relacionados com a forma de obtenção da fonte energética, mas sim fatos relacionados com dados geográficos e históricos da região afetada. Nesse contexto, se abordou ainda os problemas sociais, ambientais, políticos e econômicos, que surgiriam devido a escolha daquela fonte energética específica. Adicionalmente, aos professoresalunos foram sugeridos novas músicas e vídeos, cujos conteúdos sejam interligados e que possam ser abordados em sala de aula nos diferentes conteúdos programáticos de cada uma das disciplinas avaliadas.

Para que o conteúdo programático apresentado no vídeo seja realmente assimilado, posteriormente pode ser apresentado o vídeo pela segunda vez. Mas, durante todas as exibições o mesmo deve ser interrompido, em momentos específicos, e então realizar questionamentos sobre o que foi apresentado até o momento da interrupção da exibição do vídeo.

Ao final de cada reunião o professor-aluno respondia a dez questões, onde eram avaliados como e, em que nível cada uma dessas atividades diferenciadas poderia auxiliar o aluno motivando, o mesmo, no processo ensino-aprendizagem.

Posteriormente o professor-aluno aplicou a atividade para as turmas em que ele era professor regente. Os resultados foram relatados posteriormente utilizando relatórios sucintos, no qual o mesmo declarou as suas impressões obtidas durante o processo de aplicação da 
atividade para as suas turmas, bem como, se as atividades auxiliaram no processo ensinoaprendizagem dessas turmas.

\subsection{Atividades Lúdicas}

Atividades lúdicas foram realizadas em grupo, para avaliar quais conteúdos foram realmente assimilados pelos professores-alunos durante o processo de exposição do vídeo. Estas atividades tiveram como objetivo principal verificar o processo de assimilação dos conteúdos e reforços das informações expostas em relação àqueles que são esperados que os participantes atingissem ao final da aula.

As dinâmicas ocorreram com grupos de quatro integrantes, formados livremente por escolha dentre os participantes. Coube ao aplicador da atividade indicar as regras que regiam a atividade e também avaliar o andamento do processo em um tempo hábil delimitado.

Para avaliar se a técnica metodológica proposta auxiliou no processo de aprendizagem dos conteúdos ministrados durante as reuniões e aulas foram utilizadas duas atividades lúdicas específicas. A primeira um jogo de perguntas e respostas e a segunda um jogo da memória.

\section{a) Jogo Perguntas e Respostas}

Nesta atividade preparou-se, antecipadamente, 34 cartões que apresentavam questões e suas respectivas respostas. Esses cartões foram dispostos sobre as carteiras, cobrindo o conteúdo das perguntas e respostas (Anexo I). Cada grupo foi formado por quatros participantes, sendo que o primeiro participante disputava com o terceiro participante e o segundo participante com o quarto participante (Figura 1). Após o sorteio o primeiro participante retira um dos cartões e faz a pergunta para o terceiro participante. Caso a resposta seja a correta, o ponto será creditado para o participante que respondeu corretamente e o cartão é retirado do monte. Caso a resposta esteja errada ou incompleta, a mesma retorna para a mesa, sendo o cartão embaralhado sobre a carteira pelo segundo participante. O próximo cartão é retirado pelo segundo participante e a resposta deve ser fornecida pelo quarto participante. A atividade lúdica de Perguntas e Respostas deve continuar até que um dos participantes consiga 10 pontos.

\section{b) Jogo da Memória}

Antecipadamente foram preparados 18 cartões $(6 \mathrm{~cm} \times 12 \mathrm{~cm})$ impressos com palavras chaves sobre o tema exposto no material audiovisual e mais 18 cartões $(6 \mathrm{~cm} \times 12 \mathrm{~cm})$ impressos com imagens retiradas da internet referentes as palavras chaves sobre o tema exposto no material audiovisual.

Para cada um dos grupos formados por quatro participantes se entregou o conjunto de 36 cartões, sendo que esses cartões foram espalhados sobre a carteira com as imagens e os nomes cobertos. Realizou-se o sorteio para definir o primeiro participante, sendo que esse abriu dois cartões para verificar se os mesmos combinavam. Caso os cartões formassem o par entre o nome e a imagem esse participante marca um ponto, ficando com esse o par de cartões. Caso os dois cartões não formassem o par entre a imagem e nome, esses dois cartões eram devolvidos a mesa com imagem e nome cobertos. Essa atividade lúdica se encerra quando todos os pares são formados. 


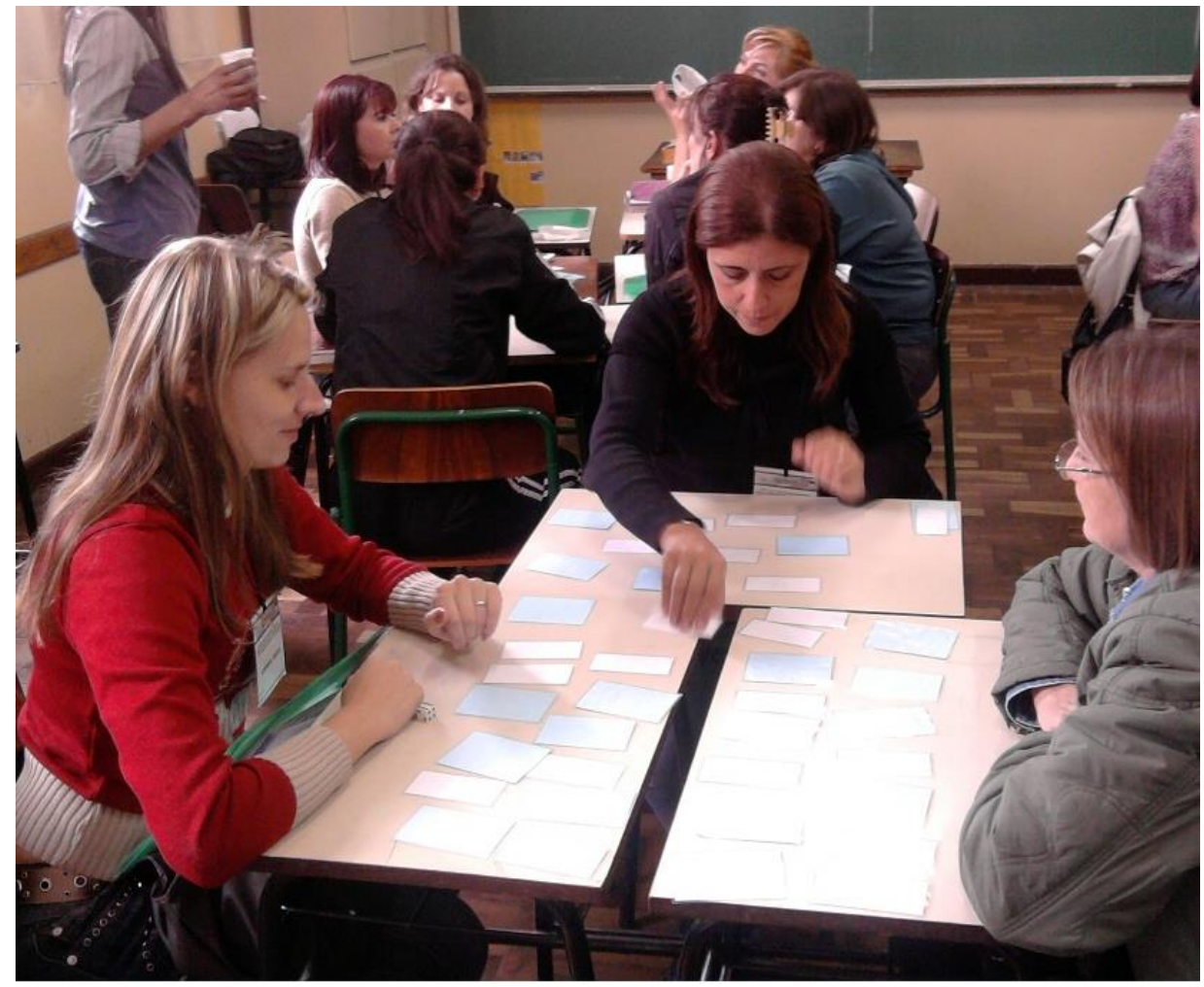

Figura 1. Aplicação da atividade Perguntas e Respostas para os professores-alunos do curso de "Capacitação de

Professores de Ciências e Química do Ensino Básico para o Desenvolvimento de Atividades Motivadoras do Aprendizado" do Programa Universidade Sem Fronteiras (Apoio as Licenciaturas) financiado pela Secretaria de Ciência e Tecnologia e Ensino Superior do Estado do Paraná (SETI), durante a segunda reunião.

\section{RESULTADOS E DISCUSSÃO}

Avaliando-se os relatórios e as pesquisas estatísticas que foram entregues por cada participante do curso de capacitação, constatou-se que ocorreu evolução no processo motivacional e de aprendizagem dos conteúdos programáticos apresentados, principalmente quando se associou as metodologias audiovisuais a forma clássica de ensino. Os professores que participaram ativamente do curso apontaram de forma categórica sobre os benefícios advindos do uso dos novos recursos metodológicos no processo ensino-aprendizagem, concordando com ideias anteriores de Rocha e Cavicchioli (2005).

Dos diferentes relatos desses professores em relação a seus alunos, estes comentam que "...foi muito melhor a fixação do conteúdo pelos alunos, quando exibido o vídeo e/ou a música, do que somente a aula teórica". Entretanto, deve-se questionar que tipo de aprendizagem foi oportunizado por estes recursos? Além de, quais as implicações destas novas metodologias para outros momentos do processo ensino-aprendizagem dentro do âmbito escolar?

Um ensino compatível com a teoria piagetiana deve ser baseado no ensaio e no erro, na pesquisa, na investigação, na solução de problemas por parte do educando e, não em aprendizagem de fórmulas, nomenclaturas e definições. A descoberta irá garantir ao sujeito a compreensão da estrutura fundamental do conhecimento. O ponto fundamental do ensino, portanto, consiste em processos e não em produtos de aprendizagem (Mizukami, 1986). Portanto, infere-se que uma didática baseada na abordagem construtivista atribuirá papel 
primordial à pesquisa por parte do aluno, pois serão durante este tipo de atividade intelectual que serão formadas as novas noções e operações.

Os professores do curso afirmaram que tais ferramentas são de fácil utilização e quando bem planejadas, seu uso apresenta resultados positivos quanto ao aprendizado de seus alunos (MORAES et al, 2012).

Na Figura 2 são apresentados os resultados obtidos após a avaliação dos questionários respondidos pelos professores-alunos ao final da segunda reunião do curso de capacitação. As questões 7 e 8 se referem a exposição do vídeo sobre " Biologia: Tudo sobre a Célula " que foi apresentado na primeira fase dessa segunda reunião. $\mathrm{Na}$ avaliação desses professores percebeuse que, a aplicabilidade dessa atividade no ensino médio é extremamente fácil e agradável. Visto que, dos vinte e quatro professores que participaram dessa reunião, dez deles indicaram nota 9 e onze indicaram nota 10, sendo que a média aritmética obtida para essa avaliação foi igual a 9,3. A avaliação do nível de dificuldade do conteúdo abordado nas "Perguntas e Respostas" (Anexo I), especificamente a questão 8 do referido questionário, foi considerado de fácil dificuldade para a maioria dos docentes, porém a média aritmética dessa avaliação foi de 8,3 , ou seja um ponto abaixo do valor de aplicabilidade indicado pelos mesmos docentes.

Para avaliar a segunda fase do processo pedagógico, correspondente a atividade lúdica denominada de "Jogo da Memória" se utilizou apenas da questão 9. Nela se verifica o quanto essa atividade facilitou a assimilação dos conteúdos abordados no vídeo sobre "Biologia: Tudo sobre a Célula", na opinião dos professores-alunos. Como resultado da avaliação desses docentes observa-se que a maioria deles considera que a atividade facilitou o aprendizado dos conteúdos abordados, tanto no referido vídeo, como na atividade de "Perguntas e Respostas". Assim, podese confirmar que o uso conjunto dessas atividades é um processo motivador de aprendizagem, além de auxiliar o aprendizado dos conteúdos abordados. Resultados esses concordantes com os relatados anteriormente por Moraes e Rocha [2012].

Ao se avaliar os relatórios produzidos pelos professores-alunos, após a aplicação das atividades para as suas turmas, percebeu-se que poucos foram os docentes que conseguiram aplicar a atividade sobre "Biologia: Tudo sobre a Célula" como esta foi concebida. Mas foi possível observar que a maioria dos professores-alunos adaptou integral ou parcialmente as atividades para conteúdos que os mesmos estavam abordando naquele momento com suas turmas. Portanto quando o professor-aluno conseguiu algum vídeo que versava sobre o conteúdo programático que ele abordava no momento ele conseguiu adaptar a atividade integralmente.

Dentre os conteúdos abordados pelos professores-alunos estão: matéria e energia, funções orgânicas, energia, energia solar, polígonos, tabela periódica, as relações métricas no triangulo retângulo e o ciclo trigonométrico. Em geral, os professores-alunos que utilizaram diferentes técnicas metodológicas para abordar o conteúdo programático, ou seja, conseguiram aplicar ou adaptar a atividade integralmente, relatam que a grande maioria dos alunos ficou motivada com a atividade aplicada e ainda indicaram que esses alunos conseguiram assimilar melhor os conteúdos apresentados. 
7) Como você avalia a aplicação do conteúdo na Primeira fase, com esta abordagem, no ensino médio.

Avaliação Média $=9,3$

Número de Respostas $=24$

\begin{tabular}{c|c|c|c|c|c|c}
\hline Avaliação & $\mathbf{5}$ & $\mathbf{6}$ & $\mathbf{7}$ & $\mathbf{8}$ & $\mathbf{9}$ & $\mathbf{1 0}$ \\
\hline Quantidade & & & 1 & 2 & 10 & 11 \\
\hline Porcentagem & & & $4,2 \%$ & $8,3 \%$ & $41,7 \%$ & $45,8 \%$ \\
\hline
\end{tabular}

8) Em sua opinião, qual o nivel de dificuldade das experiências demonstrativas na Primeira fase, para aplicação em sala de aula.

Avaliação Média $=8,3 \quad$ Número de Respostas $=24$

\begin{tabular}{c|c|c|c|c|c|c|c|c|c|c}
\hline Avaliação & $\mathbf{1}$ & $\mathbf{2}$ & $\mathbf{3}$ & $\mathbf{4}$ & $\mathbf{5}$ & $\mathbf{6}$ & $\mathbf{7}$ & $\mathbf{8}$ & $\mathbf{9}$ & $\mathbf{1 0}$ \\
\hline Quantidade & 2 & 0 & 1 & 0 & 0 & 1 & 1 & 4 & 1 & 14 \\
\hline Porcentagem & $8,3 \%$ & & $4,2 \%$ & & & $4,2 \%$ & $4,2 \%$ & $16,6 \%$ & $4,2 \%$ & $58,3 \%$ \\
\hline
\end{tabular}

9) Em sua opinião, quanto a atividade da Segunda Fase facilitou a aprendizagem dos conceitos desenvolvidos.

Avaliação Média $=9,5$ Número de Respostas $=23$

\begin{tabular}{c|c|c|c|c|c|c}
\hline Avaliação & $\mathbf{5}$ & $\mathbf{6}$ & $\mathbf{7}$ & $\mathbf{8}$ & $\mathbf{9}$ & $\mathbf{1 0}$ \\
\hline Quantidade & & & 1 & 1 & 6 & 15 \\
\hline Porcentagem & & & $4,3 \%$ & $4,3 \%$ & $26,1 \%$ & $65,3 \%$ \\
\hline
\end{tabular}

Figura 2. Representação estatística de três questões respondidas (números 7, 8 e 9) pelos professores-alunos do curso de "Capacitação de Professores de Ciências e Química do Ensino Básico para o Desenvolvimento de Atividades Motivadoras do Aprendizado" do Programa Universidade Sem Fronteiras (Apoio as Licenciaturas) financiado pela Secretaria de Ciência e Tecnologia e Ensino Superior do Estado do Paraná (SETI), durante a segunda reunião.

Em relação à aplicação do vídeo "Paraná Bio: Descobrindo os Corredores da Biodiversidade" e da música "Sobradinho" que foram utilizados como instrumentos metodológicos na terceira reunião do curso de capacitação se observou que a combinação de somente duas técnicas metodológicas, ou seja, o vídeo e a aula teórica não agradaram os professores como aconteceu com a combinação de três instrumentos metodológicos apresentados na segunda reunião. Talvez, os professores sentiram falta da atividade de "Perguntas e Respostas" ou ainda de outra atividade que a substituísse, visto que a média aritmética em que os mesmos avaliaram a aplicação do conteúdo apresentado sobre o tema "biodiversidade" foi de 6,4 (Figura 3 - Questão7). Esta nota é muito inferior àquela apresentada para a atividade similar aplicada na reunião anterior. Desta forma, os professores demonstraram que o vídeo seguido da aula teórica sobre "Formas e Fontes de Energia" não foram suficientemente elucidativas para que os alunos de ensino médio conseguissem assimilar o referido conteúdo programático e os seus desdobramentos. 


7) Como você avalia a aplicação do conteúdo na Primeira fase, com esta abordagem, no
ensino médio.
Avaliaçáo Média $=6,4$
\begin{tabular}{c|c|c|c|c|c|c|c|c|c|c} 
Nualiação & 1 & 2 & 3 & 4 & 5 & 6 & 7 & 8 & 9 & 10 \\
\hline Quantidade & 1 & & & 2 & & 2 & 2 & 8 & 7 & 4 \\
\hline Porcentagem & $3,8 \%$ & & & $7,7 \%$ & & $7,7 \%$ & $7,7 \%$ & $30,8 \%$ & $26,9 \%$ & $15,4 \%$ \\
\hline
\end{tabular}

8) Em sua opiniăo, qual o nível de dificuldade das experiências demonstrativas na Primeira fase, para aplicação em sala de aula.

Avaliaçăo Média $=7,1 \quad$ Número de Respostas $=26$

\begin{tabular}{c|c|c|c|c|c|c|c|c|c|c}
\hline Avaliação & $\mathbf{1}$ & $\mathbf{2}$ & $\mathbf{3}$ & $\mathbf{4}$ & $\mathbf{5}$ & $\mathbf{6}$ & $\mathbf{7}$ & $\mathbf{8}$ & $\mathbf{9}$ & $\mathbf{1 0}$ \\
\hline Quantidade & 2 & 1 & 2 & & 3 & 1 & 1 & 3 & 7 & 6 \\
\hline Porcentagem & $7,7 \%$ & $3,8 \%$ & $7,7 \%$ & & $11,5 \%$ & $3,8 \%$ & $3,8 \%$ & $11,5 \%$ & $27,0 \%$ & $23,2 \%$ \\
\hline
\end{tabular}

9) Em sua opiniåo, quanto a atividade da Segunda Fase facilitou a aprendizagem dos conceitos desenvolvidos.

Avaliaçăo Média $=9,0$ Número de Respostas $=26$

\begin{tabular}{c|c|c|c|c|c|c}
\hline Avaliação & 5 & 6 & 7 & 8 & 9 & 10 \\
\hline Quantidade & & 1 & 1 & 5 & 8 & 11 \\
\hline Porcentagem & & $3,8 \%$ & $3,8 \%$ & $19,2 \%$ & $30,8 \%$ & $42,4 \%$ \\
\hline
\end{tabular}

Figura 3. Representação estatística de três questões respondidas (números 7, 8 e 9) pelos professores-alunos do curso de "Capacitação de Professores de Ciências e Química do Ensino Básico para o Desenvolvimento de

Atividades Motivadoras do Aprendizado" do Programa Universidade Sem Fronteiras (Apoio as Licenciaturas) financiado pela Secretaria de Ciência e Tecnologia e Ensino Superior do Estado do Paraná (SETI), durante a terceira reunião.

Ainda, consideraram que as atividades propostas, nessa fase do curso de capacitação, não os deixaram suficientemente confortáveis com a forma que o conteúdo seria absorvido por seus alunos. Por esses motivos a média aritmética das avaliações indicadas pelos professores foi somente 7,1 (Figura 2 - Questão 8). Posteriormente a apresentação da música "Sobradinho" e ao debate desencadeado, os professores avaliaram essa segunda fase da reunião como muito produtiva, fato que refletiu na média aritmética obtida, que foi 9,0.

Essa última pontuação se refletiu nos dados apresentados pelos professores através dos relatórios produzidos após a terceira reunião. Em geral, os mesmos utilizaram mais de uma atividade metodológica, aplicadas em duas, ou, mais aulas para abordar o conteúdo em questão. De maneira contundente, os professores relatam o fator motivador que ocorre, quando são aplicadas atividades diferenciadas para desenvolver ou apresentar um conteúdo programático, bem como, essas atividades auxiliam e facilitam no processo de assimilação dos conteúdos apresentados.

\section{CONCLUSÕES}

A apresentação de vídeos educativos e músicas para motivar o aprendizado foram bem aceitos pelos professores-alunos durante o curso. Fato refletido no momento da aplicação das atividades nas turmas em que esses professores foram regentes. As metodologias específicas, ou 
seja, vídeos e música mostram-se ferramentas motivadoras apropriadas no processo ensinoaprendizagem, principalmente quando aplicadas em conjunto e/ou aplicadas em conjunto com outras metodologias.

Assim, o processo motivacional torna-se facilmente identificado quando dados estatísticos são obtidos durante todo o curso, principalmente por ser a motivação um dos objetivos intrínsecos do referido curso. A partir dos relatórios dos professores, outra ferramenta de avaliação, torna-se nítido a motivação dos mesmos, já que aplicaram a atividade desenvolvida durante o curso integralmente ou adaptada para as turmas que ministraram aulas.

Também é importante ressaltar que muitos dos professores, em função da motivação durante o curso de capacitação, adaptaram as atividades apresentadas não somente para conteúdos de Ciências e Química, mas também, para disciplinas correlatas a estas, tais como a Matemática, a Biologia e a Física. Desta forma, motivaram os alunos para o aprendizado e os auxiliaram de forma positiva para que os mesmos conseguissem absorver os conteúdos, por um período de tempo maior.

Enfim, vale ressaltar que o uso de atividades diferenciadas não retira totalmente a forma tradicional de se lecionar, ou seja, a lousa e o giz, mas sim são fatores que quando bem trabalhados se complementam, e também auxiliam na motivação dos alunos pelo processo ensino-aprendizagem. Não esquecendo que a diversidade das atividades é o ponto crucial de todo processo, visto que no momento que as atividades se tornam repetitivas o interesse e a motivação pelo ensino tende a diminuir.

\section{AGRADECIMENTOS}

Os autores agradecem a UNESPAR - Campus União da Vitória pelo auxílio e apoio para ministrar o curso de "Capacitação de Professores de Ciências e Química do Ensino Básico para o Desenvolvimento de Atividades Motivadoras do Aprendizado" e a SETI/Universidade Sem Fronteiras, Termo de Cooperação no. 214/09, pelo apoio financeiro.

\section{REFERÊNCIAS BIBLIOGRÁFICAS}

1. BEHAR, P. A, TORREZZAN, C. A. W. Metas do Design Pedagógico: Um Olhar na Construção de Materiais Educacionais Digitais. Revista Brasileira de Informática na Educação. v. 17, n. 3, p. 11-24, 2009.

2. BRASIL, Secretaria de Educação Fundamental. Parâmetros Curriculares Nacionais (Ensino Médio): Parte II - Códigos, Linguagens e suas Tecnologias. Brasília: 2000, p. 12.

3. DENZIN, N. K.; LINCOLN, Y. S. Part IV: methods of collecting and analyzing empirical materials (introduction). In: DENZIN, N. K.; LINCOLN, Y. S. (Eds.). The handbook of qualitative research. 2. ed. London: Sage, 2000, p. 632-643.

4. FALKEMBACH, G. A. M. Concepção e Desenvolvimento de Material Educativo Digital. Novas Tecnologias na Educação, v. 3, n.1, p. 1-15, 2005.

5. FONTANA, A.; FREY, J. H. The interview: from structured questions to negotiated text. In: DENZIN, N. K.; LINCOLN, Y. S. (Eds.). The handbook of qualitative research. 2. ed. London: Sage, 2000. p. 645-672. 
6. GUIMARÃES, S. E. R; BORUCHOVITCH, E. O Estilo Motivacional do Professor e a Motivação Intrínseca dos Estudantes: Uma Perspectiva da Teoria da Autodeterminação. Psicologia: Reflexão e Crítica. v. 17, n. 2, p. 143-150, 2004.

7. HUMMES, J. M., Por que é importante o ensino da música? Considerações Sobre as Funções da Música na Sociedade e na Escola. Revista da abem. 11, 17-25, 2004.

8. https://www.youtube.com/watch?v=Du2jnMi5MY4, acesso 21/03/2010a

9. http://www.youtube.com/watch?v=UqcoH9UCFMU, acesso 21/03/2010b.

10. MIZUKAMI, M. G. N. Ensino: as abordagens do processo. São Paulo: EPU,1986.

11. MORAES, S. R.; ROCHA, J. R. C. Atividade Motivadora para o Aprendizado de Conceitos de Oxidação e Redução. Holos. v. 28, n. 4, p. 250-258, 2012.

12. MORAES, S. R.; DINNIZ, A. C. Z.; GONÇALVES, I. M. S.; KASCHUK, J. J.; CRUZ, L. C.; ROCHA, J. R. C.; O Processo de Diluição de uma Solução como Metodologia Didática. Periódico Tchê Química, v. 9, n. 18, p. 57-64, 2012.

13. MORAES, S. R.; WISNIEWSKI, G.; ROCHA, J. R. C., Ciência na Praça: A Faculdade Interagindo com a Comunidade. Holos. v. 30, n. 4, p. 463-472, 2014.

14. MORAN, J. M., MASETTO, M., BEHRENS, M. Novas Tecnologias e Mediação Pedagógica. São Paulo, Papirus Editora, 2000.

15. MORAN, J. M. O Vídeo na Sala de Aula. Comunicação \& Educação. v. 2, p. 27-35,1995.

16. ROCHA, J. R. C.; CAVICCHIOLI, A. Uma Abordagem Alternativa para o Aprendizado dos Conceitos de Átomos, Molécula, Elemento Químico, Substância Simples e Substância Composta, nos Ensino Fundamental e Médio. Química Nova na Escola, v. 21, n. 1, p. 29-33, 2005.

17. SANTOS, L. M. A., TAUROCO, L. M. R. A Importância do Estudo da Teoria da Carga Cognitiva em uma Educação Tecnológica. Novas Tecnologias na Educação. v. 5, n. 1, p. 1-11, 2007.

18. SOUZA, J. (org). O que faz a música na escola? Concepções e vivências de professores do ensino fundamental. Porto Alegre: Núcleo de Estudos avançados do Programa de Pósgraduação em música - Mestrado e Doutorado da UFRGS, 2002. (Série Estudos, v.6).

19. UGIONI, M. M. O., (Monografia de Especialização) Investigação do Emprego da Mídia Informática sob a Luz de Vygostky como Elemento Motivador da Aprendizagem. Programa de Formação Continuada. Universidade Federal do Rio Grande, Florianópolis, 2009. 


\section{ANEXOS: PERGUNTAS E RESPOSTAS}

1. O que são: Membrana Celular, Citoplasma e Núcleo? Partes fundamentais das Células Eucarióticas
6. Como é denominado o conjunto de organelas celulares e hialoplasma, onde se realizam diferentes processos metabólicos? Citoplasma

7. Como é denominada a organela própria das células animais composta por dois (2) Centríolos e que participam na divisão celular e na formação de estruturas de

movimentos pelos Cílios e Flagelos? Centrossomo
Células Animais e Células Vegetais
8. Como é denominada a organela que em suas cristas contém enzimas e é responsável pela respiração celular? Mitocôndria

presença de cloroplastos, parede celular e carência de Centrossomos? Células Vegetais

4. Os animais, plantas, fungos, algas e os protozoários são formados por que tipo de células? Células eucarióticas

5. Como são formadas as células vegetais? Parede Celular, Cloroplastos e carência de Centrossomos
9. Quais são as espécies que estão associados aos Ribossomos? Retículo Liso e Retículo Rugoso.

10. Qual é a organela que se associa a síntese de proteínas? Ribossomos 
11. Qual estrutura é formada por uma dupla camada de fosfolipídios e proteínas globulares? Membrana Plasmática
16. Em que local celular são amadurecidas as vesículas até serem convertidas em Lisossomos? Complexo de Golgi
12. Qual estrutura tem a função de regular quais substâncias passam por ela, devido à sua semipermeabilidade e a recepção das informações de seu exterior? Membrana Plasmática
17. Em que local celular se encontram os vacúolos que armazenam substâncias e dão conta da osmorregulação? Hialoplasma
13. Qual estrutura participa no movimento celular, na absorção e expulsão de compostos? Membrana Plasmática
18. Qual é a espécie celular que ocupa a parte central do citoplasma em uma célula Eucariótica? Núcleo
14. Qual estrutura celular é formada por um envoltório nuclear que é uma dupla membrana atravessada por poros nucleares, que regulam o fluxo de materiais entre 0 núcleo e o citoplasma? Núcleo

15. Qual é o conteúdo do núcleo celular? Nucleoplasma
19. Qual é a espécie que se forma por uma solução coloidal composta com grande variedade de princípios ativos (nucleotídeos e enzimas)? Nucleoplasma

20. No nucleoplasma se encontram imersos que tipo de espécies? Cromatina e o Nucléolo. 
21. Qual espécie que é agregada de DNA e de proteínas que tem pequeno tamanho também denominadas Histonas? Cromatina

22. Qual é o nome que a fibra recebe no segundo nível de compactação da mesma? Solenóide

23. Qual é a espécie portadora de mensagens genéticas de cada indivíduo, encarregando-se de transmitir essa informação e toda uma série de características morfológicas e fisiológicas? DNA
26. Qual é o nível estrutural que consiste em associação de DNA com um agregado protéico do que resultam os Nucleossomos. A estrutura que formam recebe o nome de "Colar de Pérolas"? Primeiro nível de compactação da Cromatina

27. Qual é o significado do termo "DNA"? Ácido Desoxirribonucléico.

28. A fibra vai se enrolando sobre si mesma em sucessivos níveis, até adotar a forma de cromossomos, esse corresponde? Ao quinto e último nível de compactação.
24. Em qual setor celular se encontra o DNA nas células dos seres vivos? No Núcleo
29. Qual é a estrutura molecular formada por duas cadeias antiparalelas de nucleotídeos? Dupla-hélice do DNA.
25. Qual estrutura é formada pela desoxirribose-1-fosfato e mais uma base nitrogenada compõe? $\boldsymbol{A}$ estrutura dupla-hélice do DNA
30. O que são as espécies: Adenina, Guanina, Citosina e Timina? Bases nitrogenadas 
31. As bases nitrogenadas no DNA se unem e se estabilizam por qual tipo de ligação? Ligações de hidrogênio
33. Devido a complementaridade ocorre ligação da Adenina com qual base nitrogenada? Timina
32. Das múltiplas combinações possíveis entre as quatro bases nitrogenadas estruturam-se? $\boldsymbol{A}$ informação genética de cada indivíduo
34. Devido a complementaridade ocorre ligação da Citosina com qual base nitrogenada? Guanina 